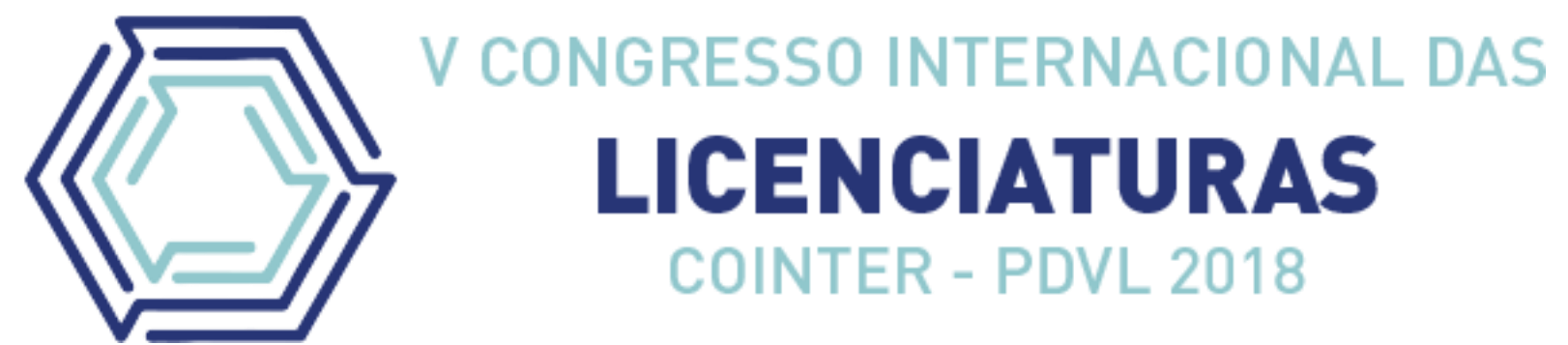

\title{
MÓDULOS INTERATIVOS DE QUÍMICA (MINQ) COMO MUSEU ALTERNATIVO PARA AMBIENTES EDUCACIONAIS
}

\section{INTERACTIVE CHEMISTRY MODULES (i-ChemMol) AS ALTERNATIVE MUSEUM FOR EDUCATIONAL ENVIRONMENTS}

\author{
Apresentação: Comunicação Oral \\ Francisco Kiuber de Oliveira Santos ${ }^{1}$, Regilany P. Colares ${ }^{2}$, Antônio Roberto Xaxier ${ }^{3}$, Júlio \\ M. Conda ${ }^{4}$ e Aluísio M. Fonseca ${ }^{5}$
}

DOI: https://doi.org/10.31692/2358-9728.VCOINTERPDVL.2018.00101

\section{Resumo (em Português ou Espanhol)}

Um dos traços característicos das sociedades ocidentais contemporâneas é o papel desempenhado pela ciência e tecnologia como elementos determinantes dos processos de desenvolvimento socioeconômico. Nesse contexto, os museus de ciência, em sua perspectiva de divulgação da informação científica para a sociedade em geral, vêm adquirindo relevância crescente. As construções da memória e do patrimônio científico-cultural efetuadas nos espaços museológicos plasmam-se em práticas relacionadas às coleções. Nunca em nenhuma outra exposição, se mostrou a importância, a forma e as informações de uma molécula, como este projeto se propõe, além de relatar a coleção, englobando o processamento técnico e as exposições nelas contidas de moléculas, átomos e suas funções no cotidiano. Dentro deste contexto, a realidade aumentada (R.A.), que é um tipo de tecnologia que permite uma visão ampliada da forma digital, percorre o mundo virtual para o real, reforçando o uso dos modelos físicos expostos.

Palavras-Chave: museu de ciência, divulgação científica, realidade aumentada, moléculas, ligações químicas.

\footnotetext{
Abstract

One of the characteristic features of the contemporary Western societies is the role played by science and technology as crucial elements of the processes of socio-economic development. In this context, the museums of science, in your perspective of dissemination of scientific

1 Licenciatura em Química, Universidade da Integração Internacional da Lusofonia Afro-Brasileira, kiubersantos@gmail.com

2 Licenciatura em Química, Universidade da Integração Internacional da Lusofonia Afro-Brasileira, regilany@unilab.edu.br

3 Mestrado Acadêmico em Sociobiodiversidade em Tecnologias Sustentáveis, Universidade da Integração Internacional da Lusofonia Afro-Brasileira, roberto@unilab.edu.br

${ }^{4}$ Ciências da Natureza e Matemática, Universidade da Integração Internacional da Lusofonia Afro-Brasileira, juliomazam22@hotmail.com

5 Doutor, Mestrado Acadêmico em Sociobiodiversidade em Tecnologias Sustentáveis, Universidade da Integração Internacional da Lusofonia Afro-Brasileira, aluisiomf@unilab.edu.br
} 
information for society in General, have been acquiring growing relevance. The construction of memory and scientific-cultural heritage carried out in Museum spaces are in practices related to collections. Never in any other exhibition, proved the importance, the form and the information of a molecule, as this project proposes, in addition to reporting the collection, encompassing technical processing and the exhibits therein of molecules, atoms and their functions in the daily life. Within this context, augmented reality (A.R.), which is a type of technology that allows for a larger view of the digital form, traverses the virtual world to the real, reinforcing the use of physical models exposed.

Keywords: museum of science, dissemination of scientific, augmented reality, molecules, chemical bonds.

\section{Introdução}

Para abordarmos a divulgação científica é essencial situá-la a priori e de forma sucinta no contexto da Comunicação Científica, uma das mais fecundas áreas de pesquisa e reflexão da Ciência da Informação. A expressão "comunicação científica" foi criada na década de 40 por John Bernal a fim de expressar "o amplo processo de geração e transferência de informação científica" entre pesquisadores (CHRISTOVÃO E BRAGA, 1997).

Sob a perspectiva de Garvey e Griffith (1979), a comunicação científica compreende ações vinculadas à produção, disseminação e uso da informação, desde a concepção que dá origem à pesquisa até sua incorporação ao corpo do conhecimento científico. O processo comunicacional ocorreria através de canais heterogêneos, formais e informais e teria como emissor o próprio gerador do conhecimento científico - pesquisador ou cientista. ${ }^{2}$ Também denominada vulgarização ou popularização da ciência, a divulgação científica, conforme destaca Bueno (1985), pressupõe o emprego de técnicas de recodificação de linguagem da informação científica e tecnológica objetivando atingir o público em geral e utilizando diferentes meios de comunicação de massa. É concebida a divulgação científica como "comunicação entre Ciência e Sociedade", sublinhando como aspecto fundamental o uso de linguagem acessível para comunicar "os fatos e princípios da Ciência". Mostafa (1981), por sua vez, adota a expressão "vulgarização científica", ressaltando a "tentativa de aproximar a ciência e suas descobertas do público leigo, isto é, dos indivíduos sem iniciação científica".

Desde os primórdios da humanidade o ser humano sempre procurou fazer representações da realidade e/ou da imaginação, podendo ser observado este comportamento através de acontecimentos, fenômenos da natureza ou até histórias de seus mitos e heróis.

Com o avanço tecnológico as formas de representação dessas expressões também progrediram. O uso do computador e a disseminação da Internet potencializou e convergiu 
tais formas de expressão, viabilizando a multimídia, que envolve textos, imagens, sons, vídeos e animações. Não demorou para que todos esses recursos rompessem com a barreira da tela do monitor, passando a gerar ambientes interativos em tempo real, através da realidade virtual e da realidade aumentada (AZUMA, 1997; KIRNER E TORI, 2004).

Realidade virtual (RV) é uma interface avançada para aplicações computacionais, que permite ao usuário navegar e interagir, em tempo real, com um ambiente tridimensional gerado por computador, usando dispositivos multissensoriais. Ou seja, a RV imerge o usuário em um ambiente tridimensional, onde é possível interagir com os elementos que estão presentes. No entanto, para que se possa “entrar" nesses ambientes, são necessários o uso de alguns aparatos tecnológicos (KIRNER E TORI, 2004).

O uso de modelos moleculares é simples e de grande valia para o propósito de ensinar, pois apoia a visualização das ligações químicas existentes entre os núcleos atômicos que compõem uma molécula, como também possibilita desenvolver no aluno do ensino fundamental e médio a percepção do arranjo espacial destas. A construção de modelos moleculares pode ser feita de várias formas e usando os mais variados materiais (LIMA E DE LIMA-NETO, 1999).

Portanto, visando aprimorar as técnicas de ensino da química a estudantes do ensino básico, quando aplicada ao estudo da formação dos esqueletos moleculares e ao arranjo espacial das moléculas, um museu interativo pode representar estruturas químicas , como por exemplo, as moléculas, objetivando desenvolver em quem os visite habilidade manual e criatividade, pois além de auxiliar no aprendizado por meio de estruturas moleculares em tamanho gigante nas suas formas espaciais, é útil para mostrar a química como uma ciência da natureza e não como uma abstração.

\section{Fundamentação Teórica}

A realidade aumentada (RA), segundo Azuma (2004), pode ser definida como um sistema que suplementa o mundo real com objetos virtuais gerados por computador, parecendo coexistir no mesmo espaço e apresentando as seguintes propriedades: a. Combina objetos reais e virtuais no ambiente real; b. Executa interativamente em tempo real; c. Alinha objetos reais e virtuais entre si, e d. Aplica-se aos sentidos, incluindo audição, tato e força e cheiro.

A realidade aumentada consiste na sobreposição de objetos virtuais gerados por 
computador em um ambiente real, utilizando para isso algum dispositivo tecnológico, como por exemplo a webcam de nosso laptop, notebook, tablete ou celular.

Deste modo, tanto a RA, como a RV são tipos de tecnologias usadas na informática. A Realidade Virtual e Aumentada são campos que iniciaram na computação abordando a percepção do mundo real com informações e dados gerados eletronicamente por meio de um computador. Essa nova tecnologia vem ganhando campo seguindo a evolução da informática (COSTA E RIBEIRO, 2009).

Analisando a evolução das diversas interfaces ao longo das décadas, percebemos que desde a revolução industrial, a humanidade teve que se adaptar às máquinas, porém, esse processo se inverteu, hoje as tecnologias da informática se tornaram uma ferramenta indispensável e até mesmo invisível aos diversos tipos de usuários. Diante desse contexto, com o surgimento da RA, como uma nova interface, usando representações tridimensionais rompendo com as limitações das interfaces existentes, possibilitando interações mais naturais. Recentemente, a evolução científica e tecnológica propiciou sua viabilização (MILGRAM et al.,1994; KIRNER E SISCOUTTO, 2007).

Por meio desta tecnologia é possível trazer os objetos virtuais do computador para o espaço do usuário, permitindo sua manipulação direta com as mãos ou por meio de elementos simples, como placas ou cubos de papel ou madeira. Nesse caso, o ensino de moléculas passa a ser potencializado, através de maior capacidade de visualização e interação com os elementos virtuais, que ocasiona em uma maior adesão aos assuntos relacionados a ligação química, moléculas ou estruturas mais complexas como o DNA. Estes objetos, virtuais, dispostos no espaço tridimensional, podem ser replicados com baixo custo por serem quase estritamente derivados de softwares (SANTIN et al., 2004).

Modelos físicos ou virtuais, são objetos de aprendizagem criados com a finalidade de interação com os conceitos reais. Com isto, é possível levar o profissional do ensino da química, a construir um conjunto de estruturas, de modo a facilitar o ensino-aprendizagem, fazendo o aluno compreender através de modelagem o real sentido de moléculas e ligações químicas.

Através desses modelos físicos é possível expressar conceitos de ligações químicas como geometria molecular, impedimento estérico, força intermolecular e estereoquímica. Através de ferramentas de softwares como o FlartoolKit, são geradas figuras do tipo VIRTUAL REALITY MODELING LANGUAGE (VRML), que é uma linguagem de 
programação que nos permite a criação de ambientes em 3D na Web, (Figuras 1a/1b-2), e desta forma auxiliar os alunos de ensino básico ou superior no aprendizado de Química (BROWN et al., 2005; SEVERINO, 2007).

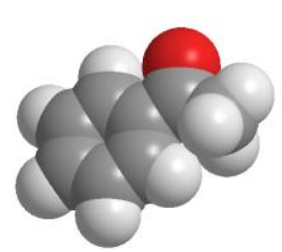

(a)

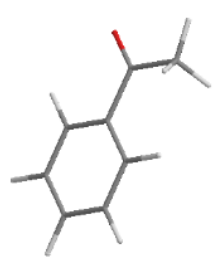

(b)

Figura 1. Modelos para interação (a) CPK e (b) Stick (Fonte: Software Weblab Pro/Autor).

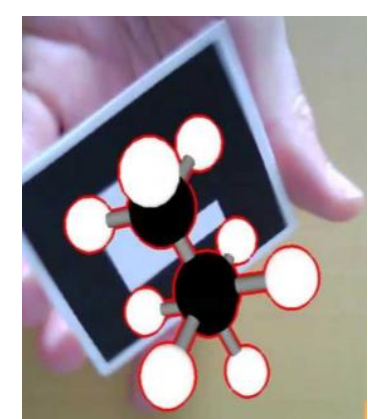

Figura 2. Etano gerado na realidade aumentada (RA) partir do programa FlartoolKit e Aumentaty Author (Fonte: Autor).

\section{Metodologia}

O método desenvolvido foi a construção de módulos interativos físicos e em RA que apresentou aos visitantes sobre a temática de moléculas (AZUMA, 1997; LIMA E DE LIMANETO, 1999). Os módulos foram realizados de forma temática, apresentando cinco tópicos (ver tabela 1). Os módulos tiveram em comum "as moléculas" e suas formas elegantes, abstratas, espaciais e geométricas. Cada tema será abordado pelos seguintes aspectos:

Qual é o tipo de molécula; Qual sua estrutura; Qual sua função; Foi obtida de fonte natural ou é sintética; ou semi-sintética; e Uma viagem ao tema (histórico da molécula). 
Tabela 1. Os módulos interativos sobre moléculas em RA.

\begin{tabular}{|l|l|}
\hline Módulo interativo 1 & $\begin{array}{l}\text { As partículas: Elétrons, Prótons, Nêutrons e outras partículas menores. } \\
\text { Como acontecem as ligações químicas: Ligação iônica, Ligação covalente } \\
\text { e Ligação metálica. }\end{array}$ \\
\hline Módulo interativo 2 & $\begin{array}{l}\text { A Geometria das ligações químicas: Os aglomerados iônicos e suas } \\
\text { principais estruturas cristalinas; A forma geométrica das moléculas. }\end{array}$ \\
\hline Módulo interativo 3 & $\begin{array}{l}\text { As formas alotrópicas do carbono: fulereno, nanotubo de carbono, grafite, } \\
\text { grafeno e diamante. }\end{array}$ \\
\hline Módulo interativo 4 & Monte sua molécula: modelos físicos com conexões. \\
\hline Módulo interativo 5 & $\begin{array}{l}\text { Use sua imaginação e interaja virtualmente com as moléculas no computador } \\
\text { através da Realidade aumentada }\end{array}$ \\
\hline
\end{tabular}

\subsection{Local dos módulos}

Os módulos foram instalados inicialmente no Instituto de Ciências Exatas e da Natureza (ICEN), no Campus dos Palmares (Acarape-CE), da Universidade da Integração Internacional da Lusofonia Afro-Brasileira (UNILAB).

\subsection{Softwares utilizados para os modelos moleculares}

Foram utilizados os seguintes softwares com o objetivo do ensinar aos visitantes que tiverem interesse, a utilização do referido programa assim como suas potencialidades. Entre eles: ACD/ChemSketch 12: É um software gratuito que pode editar estruturas planas assim com estruturas moleculares em 3-D; Chemwindow 6: O chemwindow cria estruturas planares e moléculas orgânicas ou inorgânicas e o Chemdraw 12: O chemdraw é um software livre que permite criar moléculas de vários tipos, editá-las, e gerar espectros de ressonância magnética nuclear de hidrogênio e carbono.

\subsection{Estrutura dos modelos}

\subsubsection{Modelos Expositores}

Os modelos moleculares, pintados com tinta florescente, foram fixados sobre mesas adaptadas, com iluminação de luz negra na sua parte inferior (Figura 3). Os modelos estavam distribuídos de vários tamanhos para uma melhor visualização, Figura 4. 


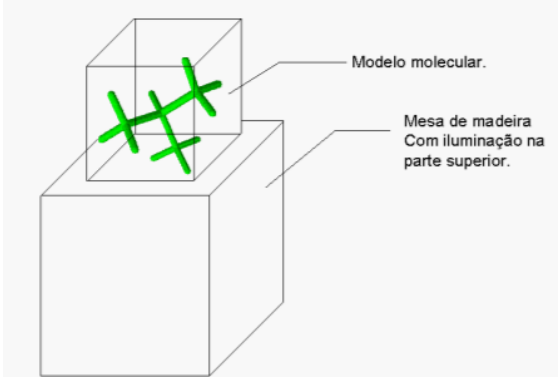

Figura 3. Modelos de estruturas do museu interativo.
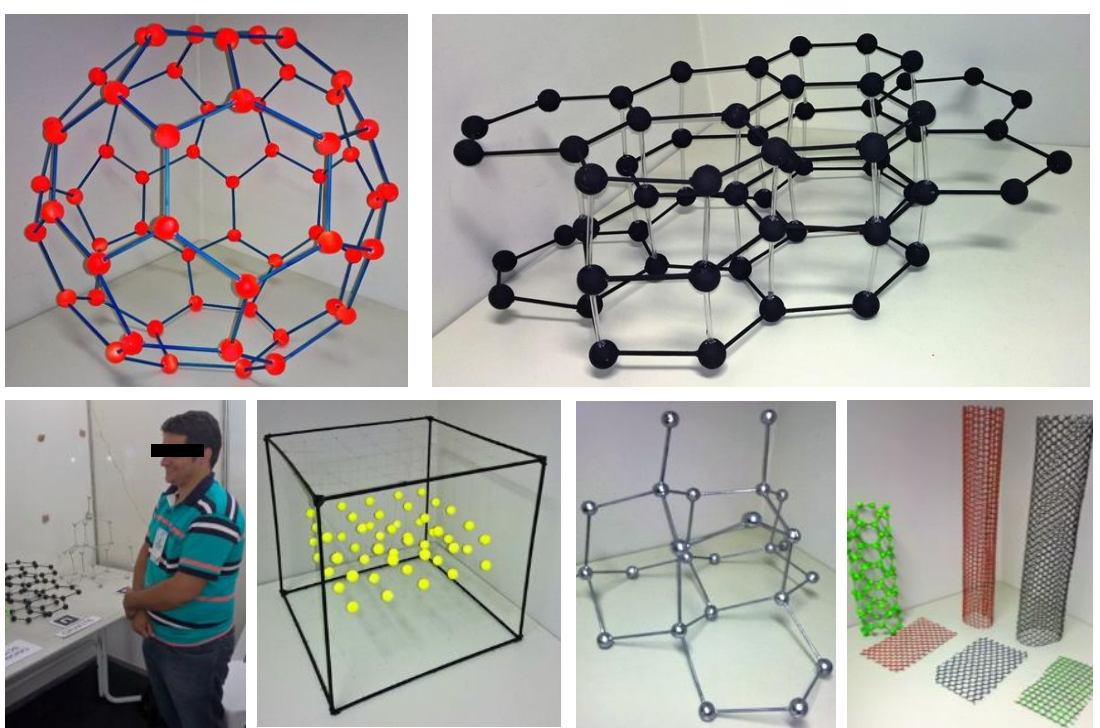

Figura 4. Vários modelos de estruturas do museu interativo.

\subsubsection{Modelos Interativos e de RA:}

Os modelos físicos que representaram as moléculas na forma interativa foram postos nas mesas através de placas interativas que quando visualizadas pelo software são convertidas em moléculas pelos visitantes, de acordo com os protótipos encontrados e guiados pelos monitores ou manuais. Esses modelos foram criados com tamanhos variados para melhor visualização, como mostra a Figura 5. 


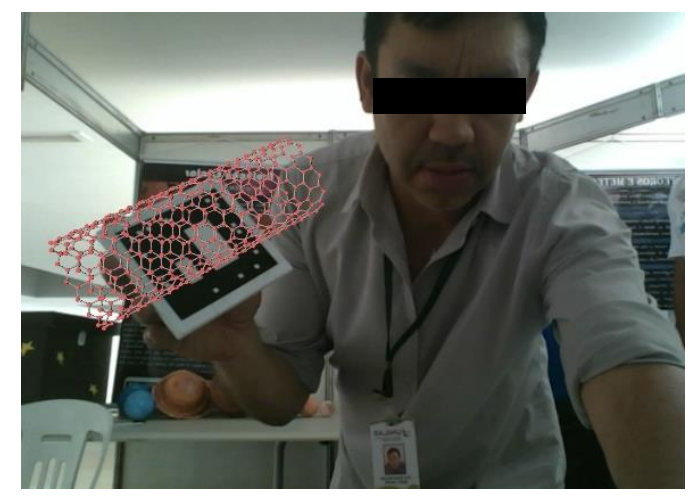

Figura 5. A representação de um dos módulos interativos físicos e virtuais através da RA.

\section{Resultados e Discussão}

O museu interativo envolveu o trabalho sobre o desenvolvimento das moléculas e sua formação através da ligação química com uma interface no meio ambiente. A divulgação da química orgânica se baseou em modelos de três dimensões (3-D). A atividade em questão mostrou-se como ação suplementar às desenvolvidas em sala de aula, para os alunos, e para os leigos, ou pessoas que não tem conhecimento de ciência ou química, contribuindo para despertar o interesse de todos para vida cultural e científica.

Nos módulos interativos os visitantes puderam observar, criar algumas estruturas tanto por modelos moleculares como por computador. Sendo as responsáveis pelos "efeitos visuais", que geraram a motivação, pois foram usadas aquelas demonstrações que deixaram todos admirados com a beleza, complexidade e interatividade.

Os executores do museu foram responsáveis pela explanação e condução dos visitantes para os módulos interativos. Cabendo ao proponente, a organização geral da estruturação dos módulos, a organização e o estabelecimento de contatos nas escolas.

A receptividade dos participantes (alunos e professores), o número de pessoas que assistiu e desenvolveu cada módulo, o entendimento dos ouvintes em relação às questões químicas sugeriu que a divulgação, de certa forma, atingir seus objetivos e que o grupo do Museu conseguiu sua contribuição.

As atividades realizadas agregaram a comunidade de modo geral Acarape, e o entorno do Maciço do Baturité. O que significou que abrangeu toda a rede de ensino do município de 
Acarape, a comunidade local e a dos municípios adjacentes. Levando-se em conta a localização do Museu interativo na UNILAB, na cidade de Acarape, a acessibilidade de pessoas com deficiências e o alcance proposto às series iniciais os módulos interativos aqui apresentados teve um público-alvo bastante amplo e eclético. Considerando apenas alunos e professores da rede pública das zonas urbana e rural do referido município e das cidades mais próximas, dentro de um raio de $50 \mathrm{~km}$, estimou-se um público, entre estudantes e professores, de 1.500 (mil e quinhentas) pessoas atendidas pelo Museu ao longo dos doze primeiros meses de funcionamento.

\section{Conclusões}

O Museu se correlacionou com a sociedade, na medida em que as suas ações articularam a formação inicial e complementar dos estudantes de licenciatura do curso de Ciências da Natureza e Matemática. Discutiu-se com a comunidade de um modo geral o currículo e os projetos pedagógicos das escolas locais (no que diz respeito ao ensino de ciências e suas tecnologias) e a própria matriz curricular dos cursos de graduação. Somandose a isto, surgiu também a consolidação de um ambiente fértil para a pesquisa colaborativa em ensino de ciências, uma vez que a instalação dos módulos interativos e a divulgação científica num ponto estratégico da cidade promoveu o estreitamento das relações entre Universidade, Escola e Sociedade, facilitando a troca de informações e experiências entre o saber acadêmico e o "chão da escola"; além de servir como instrumento para complementar o ensino de ciências na educação básica inclusive na formação continuada de professores.

\section{Referências}

AZUMA, R.A Survey of Augmented Reality, Presence: Teleoperators and Virtual Environments, v.6, n. 4, p. 355-385, 1997.

BROWN, T.L., LEMAY JR, H.E., BURSTEN, B.E., BURDGE, J.R., Química: A ciência Central, 9. ed., São Paulo: Pearson Education, 2005. p. 20.

BUENO, W. C. Jornalismo científico: conceitos e funções. Ciência e Cultura, v. 9, n. 37, p. 1420-1428, 1985. 
CHRISTOVÃO, H.T., BRAGA, G.M. Ciência da Informação e Sociologia do Conhecimento Científico: a intertematicidade plural (Sobre "A ciência e seu público" de Lea Velho: um ponto de vista de Ciência da Informação). Transinformação, v. 9, n. 3, p. 33-45, 1997.

COSTA, R.M., RIBEIRO, M.W.S. Aplicações de Realidade Virtual e Aumentada. XI Simpósio de RV e RA. Porto Alegre: SBC, 2009.

GARVEY, W.D. Communication: the essence of science. London: Pergamon Press, 1979. $332 \mathrm{p}$

KIRNER, C., SISCOUTTO, R. Realidade Virtual e Aumenta. Conceitos Projetos e Aplicações.IX Simpósio de RV e RA. Petrópolis-RJ:SBC, 2007.

KIRNER, C., TORI, R. Introdução à Realidade Virtual, Realidade Misturada e Hiperrealidade. In: Claudio Kirner; Romero Tori. (Ed.). Realidade Virtual: Conceitos, Tecnologia e Tendências. 1ed. São Paulo, v.1, p. 3-20, 2004.

LIMA, M.B., DE LIMA-NETO, P. Construção de Modelos para Ilustração de Estruturas Moleculares em Aulas de Química, Química Nova, v. 22, n. 6, 903-906, 1999.

MILGRAM, P., TAKEMURA, H., UTSUMI, A., KISHINO, F. Augmented Reality: A Class of Displays on the Reality-Virtuality Continuum. Telemanipulator and Telepresence Technologies, SPIE, v.2351, 1994.

MOSTAFA, S.P. Vulgarização Científica: mistificação da ciência ou educação permanente? Ciência e Cultura, v. 6, n. 33, p. 842-846, 1981.

SANTIN, R., KIRNER, C., GARBIN, T.R., DAINESE, C.A. Ações interativas em Ambientes de Realidade Aumentada com ARToolKit. Proc. of VII Symposium on Virtual Reality, SP, outubro. 2004.

SEVERINO, A.J., Metodologia do Trabalho Científico, 1. ed., São Paulo: Editora Cortez, 2007. 